ORIGINAL ARTICLE

\title{
Evaluation of the mercury exposure of dental amalgam patients by the Mercury Triple Test
}

\author{
G Hansen, R Victor, E Engeldinger, C Schweitzer
}

Occup Environ Med 2004;61:535-540. doi: 10.1136/oem.2003.009555

See end of article for authors' affiliations

.....................

Correspondence to: $G$ Hansen, Laboratoire d'Hygiène du Milieu et de Surveillance Biologique, Laboratoire National de Santé, 42 , rue du Laboratoire, L-1911 Luxembourg, Luxembourg; gilbert.hansen@lns.etat.lu

Accepted 28 November 2003

\begin{abstract}
Aims: To establish and analyse reference data for the mercury burden of patients with and without amalgam fillings.

Methods: Atomic absorption spectroscopy was used to quantify $\mathrm{Hg}$ concentrations in the scalp hair and urine (before and after application of dimercaptopropane sulphonate), and $\mathrm{Hg}$ release from dental amalgams (using a newly developed, amalgam specific chew test), in 2223 subjects.

Results: 50 th centiles were $1.3 \mu \mathrm{g} \mathrm{Hg} / \mathrm{g}$ creatinine in basal urine, $32 \mu \mathrm{g} \mathrm{Hg} / \mathrm{g}$ creatinine after DMPS application, $454 \mathrm{ng} \mathrm{Hg} / \mathrm{g}$ in hair, and $27 \mu \mathrm{g} \mathrm{Hg}$ per g of chewing gum, which corresponds to about $1 \mu \mathrm{g} \mathrm{Hg}$ released per minute of chewing. Total $\mathrm{Hg}$ intake (from ambient air, drinking water, food, and amalgams) of most patients is well below the provisioned tolerable weekly intake (PTWI) defined by the $\mathrm{WHO}$, unless extremely $\mathrm{Hg}$ rich food is consumed on a regular basis. However, for patients exceeding the 75thcentile in chew tests, total $\mathrm{Hg}$ intake exceeds the PTWI by about $50 \%$, even at the low limit of intake from food. In the absence of occupational exposure, significant $\mathrm{Hg}$ release from dental amalgams is a necessary but insufficient condition to obtain a high long term body burden. After removal of dental amalgams, chew tests no longer exhibit oral $\mathrm{Hg}$ exposure, while basal urine $\mathrm{Hg}$ content and DMPS induced excretion display a exponential decrease (half life about 2 months in both cases).

Conclusions: A standardised procedure for evaluation of the magnitude and origin of the $\mathrm{Hg}$ burden of individuals has been developed, which, by comparison with the database presented here for the first time, can serve as a diagnostic tool.
\end{abstract}

S ince the environmental disaster in Minamata in the 1950s, it is well established that excessive exposure to organic mercury can cause dramatic health effects including neurological, immune, motor, sensory, and behavioural dysfunctions. ${ }^{1}$ More recently, it has been speculated that, additionally, relationships may exist between several well known neurological pathologies and inorganic $\mathrm{Hg}$ exposure of patients. For example, Leong and colleagues ${ }^{2}$ showed that in vitro exposure of rat brains to $\mathrm{Hg}$ induces molecular lesions similar to those observed in brains of patients with Alzheimer's disease, and a comparative study of Bernard and colleagues ${ }^{3}$ suggested that autism may be a form of mercury poisoning. However, the influence of subtoxic levels of $\mathrm{Hg}$ is far from being established, and has been the subject of numerous controversies, especially since nonnegligible amounts of $\mathrm{Hg}$ are contained in preservatives added to many vaccines; also, small amounts of $\mathrm{Hg}$ are known to be continuously released from dental amalgam fillings. It has been estimated that two thirds of the $\mathrm{Hg}$ burden of non-occupationally exposed adults is due to amalgams; ${ }^{4}$ several authors have reported correlations between the number of amalgams and $\mathrm{Hg}$ concentration in blood plasma, urine, faeces, saliva, oral air, pituitary gland, brain occipital cortex, renal cortex, and liver of patients, ${ }^{5}$ and even between the number of amalgams in mothers and $\mathrm{Hg}$ concentration in fetal and infant livers and brains. ${ }^{6}$

However, there is very little evidence for direct health effects related to amalgam fillings. While a few examples of relief from significant symptoms following removal of amalgams seem to be established, there is very little general information on the effects of long term exposure to significant but subtoxic levels of $\mathrm{Hg}$. This has caused a situation where dental associations, governments, and numerous independent associations are defending rather contradictory positions as to whether dental amalgams might be harmful. For example, the American Dental Association has recently supported a statement that "getting rid of amalgam would be like getting rid of aspirin", ${ }^{7}$ whereas several European governments have banned use of amalgams in children, women of childbearing age, and renal patients. Recently, a general ban of "self-made" fillings (amalgams prepared by dentists themselves from roughly conditioned starting material) has been introduced in France. ${ }^{8}$

One of the major causes for the lack of unequivocal information may be the poor comparability of reference data on $\mathrm{Hg}$ concentrations in body liquids and organs of exposed and non-exposed subjects, which complicates the interpretation of the corresponding data of individual patients, and the study of relationships between $\mathrm{Hg}$ exposure and symptoms. For example, several authors have analysed Hg concentrations in basal urine, which are believed to reflect a long term body burden. ${ }^{9}{ }^{10}$ Most interesting results were obtained when $\mathrm{Hg}$ excretion was determined following administration of a chelating agent such as dimercaptopropane sulphonate (DMPS), which promotes renal excretion of a number of metals including mercury. ${ }^{11-13}$ Such investigations established, for example, correlations between $\mathrm{Hg}$ excretion and the number of amalgam fillings in patients-even though filling quality was shown to be just as determinative. ${ }^{11-13}$ Most studies have expressed $\mathrm{Hg}$ concentrations in urine relative to those of creatinine, ${ }^{10}{ }^{11}$ but others preferred absolute $\mathrm{Hg}$ concentrations. ${ }^{12}$ Also, many different doses and ways of DMPS administration have been used, and, as a consequence, results from different studies or different laboratories are often extremely difficult to compare.

Other investigations have focused on mercury concentrations in hair, which are deemed to reflect a medium term

Abbreviations: DMPS, dimercaptopropane sulphonate; PTWI, provisioned tolerable weekly intake 
body burden, since Hg is deposited in hair as it grows. Hair is believed to be a major path for excretion of toxic metals, ${ }^{14}$ and high amounts of $\mathrm{Hg}$ in hair were found to correlate with neurological dysfunction. However, measurements in urine and hair do not provide information on the actual origin of $\mathrm{Hg}$, and are thus unsuitable to explain the origin of the body burden of an individual patient.

If mercury is released from dental amalgams, measurements in the saliva should be of interest. In the much talked about Tübingen study on dental amalgams, Hg concentration in the saliva of nearly 20000 subjects was found to correlate linearly with the number of amalgam fillings, suggesting that the $\mathrm{Hg}$ burden is directly related to the number of amalgams. ${ }^{15}$ However, $\mathrm{Hg}$ concentrations from other body liquids were not available, and thus no information on $\mathrm{Hg}$ uptake could be given. Also, quantitative analysis of mercury in saliva is difficult because measurements display a poor reproducibility. ${ }^{16}$

Thus, the large number of uncertainties associated with individual measurements makes it clear that determination of $\mathrm{Hg}$ concentration in one body liquid or organ is insufficient to evaluate the degree of $\mathrm{Hg}$ exposure of a patient, or to serve as a diagnostic tool. As a consequence of the heated discussions in the early 1990s on possible health effects associated with amalgam fillings, we have established, in 1995, a standardised procedure (the Mercury Triple Test) for measurement of $\mathrm{Hg}$ levels contained in urine (before and after application of DMPS) and hair, and of $\mathrm{Hg}$ released from dental fillings, in order to establish reference data for the $\mathrm{Hg}$ burden of the Luxembourg population and to provide physicians with dependable information on relative levels of $\mathrm{Hg}$ in individual patients. This test, which has been carried out in its standardised and unchanged form in our laboratories from 1996 to 2002, on medical prescription for all patients of this country (and about 50 patients from neighbouring countries), has provided a wealth of information on absolute and relative Hg levels in patients with and without amalgam fillings, and with and without symptoms that may be related to $\mathrm{Hg}$ exposure. We present here the results of all analyses carried out in 2223 patients during this period.

It should be noted that implementing thorough medical analyses for evaluating the patients' overall health status or suggesting any therapeutic measures as a result of the Mercury Triple Test outcome would clearly exceed the scope of this study.

\section{SUBJECTS AND METHODS}

Standardised quantification of $\mathrm{Hg}$ excretion in urine and of $\mathrm{Hg}$ release from dental fillings was performed in 2223 patients, during the period 1996 to 2002. Since 1998, we additionally carried out systematic analysis of the $\mathrm{Hg}$ content of scalp hair samples of all (1709) patients. All tests were carried out at the Laboratoire National de Santé in Luxembourg, under identical conditions, ensuring comparability of results.

Urine samples were collected before food and drink, at 730 am (basal urine sample or urine I). Dimercaptopropane sulphonate (DMPS, Dimaval, Heyl) was administered orally (200 mg for patients weighing $<60 \mathrm{~kg}, 300 \mathrm{mg}$ for those $60-$ $80 \mathrm{~kg}, 400 \mathrm{mg}$ for those $>80 \mathrm{~kg}$ ), together with $0.5 \mathrm{l}$ of commercial mineral water (Vittel). Two hours later, patients drank an additional $0.5 \mathrm{l}$ of Vittel, and their urine (urine II) was collected over a four hour period following administration of DMPS.

Determination of urinary $\mathrm{Hg}$ concentration before and after application of DMPS was carried out by microwave digestion in a Paar Physica System and by cold vapour atomic absorption spectrometry using reduction by tin chloride in a
Perkin Elmer Fims 400 atomic absorption photometer. A 1 ml sample of urine was mineralised with $2 \mathrm{ml} \mathrm{HNO}_{3} 65 \%$ (Merck Suprapur), $0.5 \mathrm{ml} \mathrm{HCl} \mathrm{30 \%} \mathrm{(Merck} \mathrm{Suprapur),} \mathrm{and}$ $\mathrm{l} \mathrm{ml} \mathrm{H}_{2} \mathrm{O}_{2} 30 \%$ (Merck p.a.) for 30 minutes in closed quartz vessels according to the standard hair mineralisation programme. The clear solution was cooled down and ready for use in AAS analysis under standard conditions. For calibration a certified aqueous mercury atomic absorption calibrator from Perkin Elmer ( $1 \mathrm{~g} \mathrm{Hg} / 1 \mathrm{l} \% \mathrm{HNO}_{3}$ ) was used in appropriate dilutions. Internal quality control was assured by Biorad and Utak commercial control urines taken throughout the procedure.

One piece of chewing gum (Wrigley's doublemint chewing gum) was chewed by the patient for 30 minutes, following which $300 \mathrm{mg}$ of chewed gum was added to $1 \mathrm{ml} \mathrm{3 \%} \mathrm{HCl}$ (Merck Suprapur, diluted), and then treated and analysed as described for urine analysis. In order to optimise reproducibility of this test, only well chewed gums were considered. A significant number of tests showed that regular chewing during 30 minutes reduces the mass of gum from $3.5 \mathrm{~g}$ to about $0.9 \mathrm{~g}$; a larger mass is considered a result of insufficient chewing. Two volunteers performed at least seven standardised chew tests within a time interval of four months; fluctuations of less than $5 \mu \mathrm{g} \mathrm{Hg}$ per g of gum were observed in both cases. Determination of $\mathrm{Hg}$ concentration in the saliva of both volunteers, using a procedure similar to that described by Krauss and colleagues, ${ }^{15}$ gave significantly larger fluctuations and insufficient reproducibility. Hence, it is generally recommended to quantify oral $\mathrm{Hg}$ exposure by measuring $\mathrm{Hg}$ concentration in a chewed piece of gum, rather than in the saliva of the patient. Besides reproducibility, one major advantage of this method is the possibility for selective determination of $\mathrm{Hg}$ release from individual fillings, by selective chewing of the gum using a minimum of teeth.

Samples of about $300 \mathrm{mg}$ of scalp hair provided by the patient were washed with bidistilled water, $3 \% \mathrm{HCl}$ solution, and acetone in order to minimise external contamination. The dried material was added to $1 \mathrm{ml} 3 \% \mathrm{HCl}$ and mineralised in a Paar Physica microwave oven, similar to the procedure used for urine and chewing gums. Mercury concentrations were determined by AAS, as described above.

Analytical validation of the whole procedure was achieved by determining the mercury content of BCR (currently IRMM) certified reference material as CRM 397 trace elements in human hair, CRM 422 trace elements in cod muscle, and CRM 414 trace elements in plankton. The values found were in good agreement with those from the analysis certificates.

Valid mercury determination in urine (and by extension in hair and gum, since the same standard operating procedure is used) was certified through participation in official external quality survey programmes for trace elements in urine of the German Society for Clinical Chemistry-Reference Institution for Bioanalytics (SP2/02, one year valid certification) as well as by scoring 56/71 (our result/highest possible) and ranking 7 out of 32 labs in the six monthly cumulative report of UK NEQAS for Trace Elements (October 2001-March 2002) from the Centre for Clinical Science and Measurement at the University of Surrey, Guildford, UK.

\section{RESULTS}

Statistical data on basal urine Hg content, DMPS test, chew test, and hair test based evaluation of the Hg burden of 2223 patients (1709 patients for hair test) are listed in table 1 , and the corresponding distributions are shown in fig 1.

Maximum $\mathrm{Hg}$ concentrations determined in basal urine (first morning urine) were significantly below toxic levels. For example, the BAT value (high limit for a healthy subject occupationally exposed, as proposed by the Deutsche 

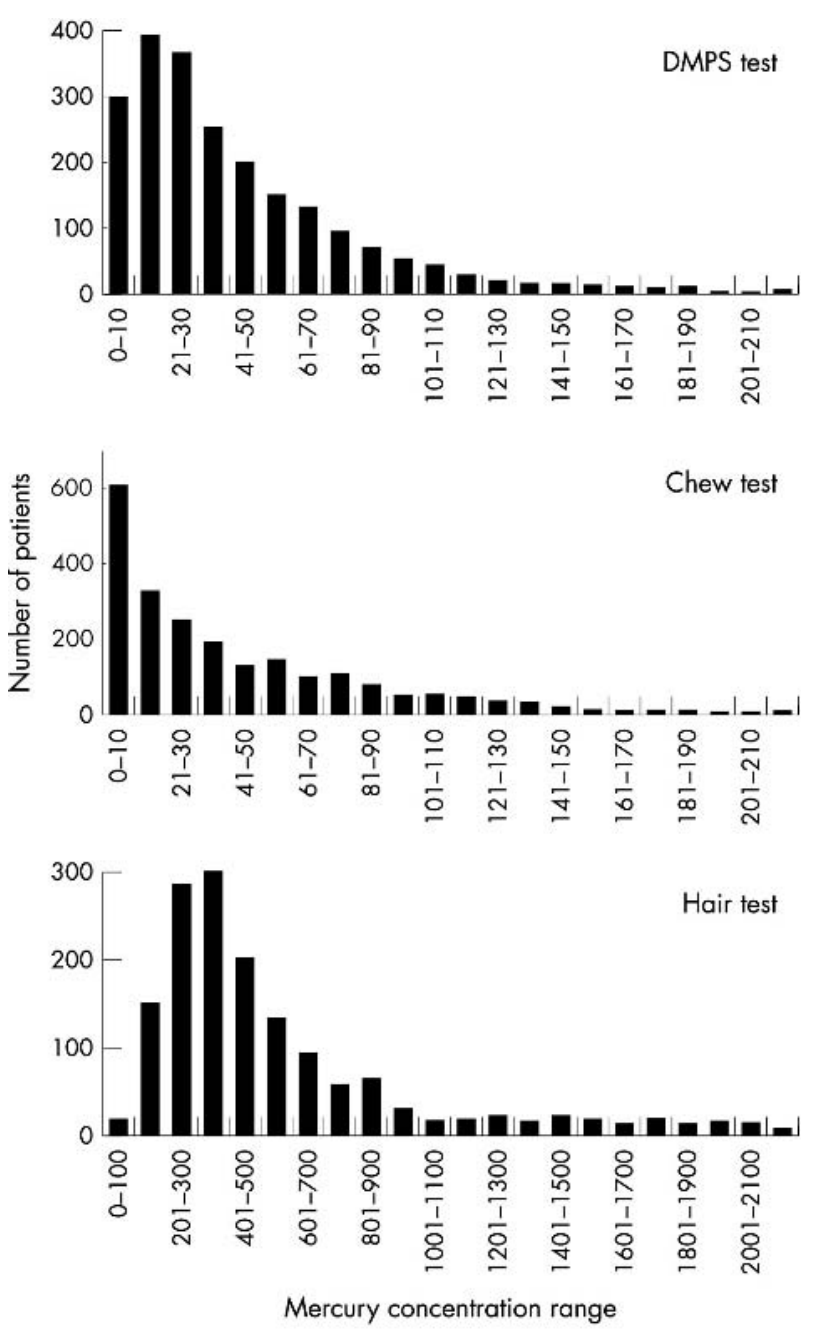

Figure 1 Distribution of $\mathrm{Hg}$ concentrations in DMPS tests $(\mu \mathrm{g} \mathrm{Hg} / \mathrm{g}$ creatinine), chew tests ( $\mu \mathrm{g} \mathrm{Hg} / \mathrm{g}$ chewing gum), and hair tests $(\mathrm{ng} \mathrm{Hg} / \mathrm{g}$ hair).

Forschungsgemeinschaft) for $\mathrm{Hg}$ in urine is $100 \mu \mathrm{g} / \mathrm{l}$ (that is, about $100 \mu \mathrm{g} / \mathrm{g}$ creatinine). ${ }^{17}$ Thus, no patients suffering from mercury poisoning are included in our study. However, most patients exhibited a non-negligible long term body burden; very few patients excreted only negligible $\mathrm{Hg}$ following administration of DMPS. As shown in table 1, the 25th-75th centile range of the non-Gaussian distribution corresponds to $17-61 \mu \mathrm{g} \mathrm{Hg} / \mathrm{g}$ creatinine. Although a low median value (454 $\mu \mathrm{g} \mathrm{Hg} / \mathrm{g}$ ) was found for the hair test, values in 56 patients were found to exceed the limit of $3600 \mathrm{ng} \mathrm{Hg} / \mathrm{g}$ hair proposed by Schiwara and colleagues. ${ }^{18}$ However, no correlation was found between DMPS test and hair test data for these patients; hence, high concentrations in hair of some subjects in this group might partially be the result of exogenous $\mathrm{Hg}$ sources.

The chew test revealed that, in the largest group of patients, no significant oral $\mathrm{Hg}$ release occurred. Patients who have never had any amalgam fillings, or patients who had their amalgams removed or overcrowned, showed no measurable Hg release. Since the chew test used here differs significantly from other chew tests, where, for example, $\mathrm{Hg}$ determinations are made in the saliva, ${ }^{10}{ }^{11}$ comparison with data from other investigations was not possible. The advantage of the present test over other chew tests is that it allows direct estimation of the amount of $\mathrm{Hg}$ specifically released from amalgams. At the 50th centile value of $27 \mu \mathrm{g}$ $\mathrm{Hg} / \mathrm{g}$ gum, about $\mathrm{l} \mu \mathrm{g}$ of $\mathrm{Hg}$ is released per minute of chewing; the maximum value of $393 \mu \mathrm{g} \mathrm{Hg} / \mathrm{g}$ gum corresponds to about $16 \mu \mathrm{g} / \mathrm{min}$. It should be noted, however, that the proportion of $\mathrm{Hg}$ attached to the gum per $\mathrm{Hg}$ released from dental fillings is unknown; hence, these data should be regarded as lower limits for $\mathrm{Hg}$ release.

The strong dependency between the amount of $\mathrm{Hg}$ extracted from dental amalgams by chewing gum during the chew test and the number of amalgams present, nicely illustrates the validity of this test as a model for $\mathrm{Hg}$ release during food consumption. The boxes in fig 2 denote the $\mathrm{Hg}$ concentration range between the 25th and the 75th centiles, while the vertical lines represent the total concentration range. The diagram confirms that amalgam-free patients display no detectable amounts of $\mathrm{Hg}$ release during the chewing process $(25$ th and 75 th centile $<0.1 \mu \mathrm{g} / \mathrm{g}$ chewing gum; these patients had had their amalgams removed for 2 months -5 years at the time of analysis).

Our results also show that other parameters besides $\mathrm{Hg}$ release from amalgams must contribute to the $\mathrm{Hg}$ body burden. This is illustrated in a plot of chew test data versus DMPS test data (see fig 3).

There seems to be no simple correlation between the data from chew tests and those from DMPS tests-that is, between the amount of $\mathrm{Hg}$ continuously released from dental fillings and the long term body burden. This is particularly surprising, because it has been previously shown that $\mathrm{Hg}$ concentration in the saliva correlates with the number of amalgam fillings, ${ }^{15}$ and that the amount of $\mathrm{Hg}$ in organs and body liquids is a function of the number and quality of amalgam fillings. ${ }^{11-13}$ Our results, in contrast, show that there are significant differences between individual subjects in the ratio of $\mathrm{Hg}$ incorporated in the body per $\mathrm{Hg}$ released from fillings. Several groups of patients can be distinguished in fig 3; the only patients with no oral $\mathrm{Hg}$ release are those without amalgam fillings. A relatively broad distribution of

\begin{tabular}{|c|c|c|c|c|}
\hline & $\begin{array}{l}\text { Basal urine } \\
\mu \mathrm{g} \mathrm{Hg} / \mathrm{g} \text { creatinine }\end{array}$ & $\begin{array}{l}\text { DMPS test } \\
\mu \mathrm{g} \mathrm{Hg} / \mathrm{g} \text { creatinine }\end{array}$ & $\begin{array}{l}\text { Chew test } \\
\mu \mathrm{g} \mathrm{Hg} / \mathrm{g} \text { chewing gum }\end{array}$ & $\begin{array}{l}\text { Hair test } \\
\text { ng Hg/g hair }\end{array}$ \\
\hline 95th centile & 4.4 & 134 & 134 & 3214 \\
\hline 75th centile & 2.1 & 61 & 63 & 869 \\
\hline 50th centile & 1.3 & 32 & 27 & 454 \\
\hline 25th centile & 0.7 & 17 & 9 & 291 \\
\hline Mean value & 1.7 & 47 & 43 & 904 \\
\hline $\begin{array}{l}\text { Standard } \\
\text { deviation }\end{array}$ & 1.7 & 51 & 48 & 1455 \\
\hline Minimum value & 0 & 0 & 0 & 20 \\
\hline Maximum value & 21 & 837 & 393 & 32557 \\
\hline
\end{tabular}




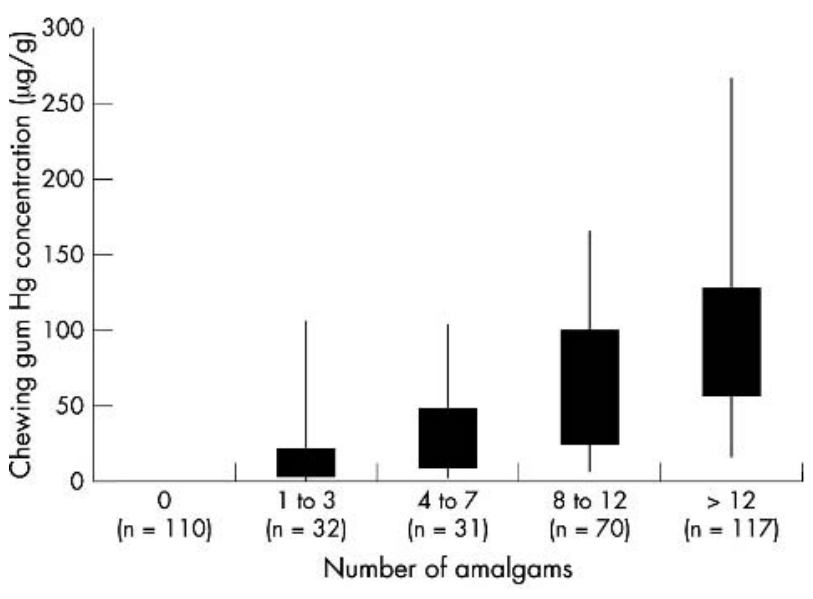

Figure 2 Box plot representing the relation between the number of amalgam fillings and $\mathrm{Hg}$ released into chewing gum. Rectangles $=$ $25-75$ th centile range; vertical lines $=5-95$ th centile range.

DMPS values is observed in this group, depending on the degree of environmental exposure of the patient. However, no patient in this group displays extremely high DMPS data (that is, significantly above the 95th centile value). This underscores the importance of the contribution of dental amalgams to the overall $\mathrm{Hg}$ burden. Several patients with low chew test values (that is, less than $10 \mu \mathrm{g} \mathrm{Hg} / \mathrm{g}$ gum) and high DMPS data (more than $150 \mu \mathrm{g} \mathrm{Hg} / \mathrm{g}$ creatinine) had their amalgams removed less than two months previously (see below for a discussion of $\mathrm{Hg}$ kinetics following amalgam removal). Some patients with significant occupational exposure (including dentists and dental assistants), display relatively high (but not extreme) values in DMPS tests (that is, between the 50th and 95th centiles), but all of them displayed low oral $\mathrm{Hg}$ exposure, due to small numbers of amalgams and/or undamaged fillings. Figure 2 shows clearly that only patients with significant oral exposure display extreme DMPS test values, thus showing that $\mathrm{Hg}$ release from dental amalgams is a necessary but insufficient condition to obtain a high long term $\mathrm{Hg}$ body burden in the absence of extreme occupational or environmental exposure. High chew test and high DMPS test data are a clear indication for significant $\mathrm{Hg}$ uptake as a consequence of $\mathrm{Hg}$ release from dental amalgams.

No correlation was observed between data from hair tests, and those from DMPS or chew tests. Hair tests provide a good indication for medium term exposure, as the $\mathrm{Hg}$ burden is monitored over a period whose length depends on the length of hair of the patient. The lack of correlation of these data with those from chew tests indicates that continuous $\mathrm{Hg}$ release from amalgams represents a minor contribution to the $\mathrm{Hg}$ incorporated in hair (that is, other sources are more important); the absence of correlation with that from DMPS tests also supports this conclusion, and shows that $\mathrm{Hg}$ concentration in hair does not necessarily reflect the overall body burden.

One of the most interesting tests for the body burden is believed to be the determination of $\mathrm{Hg}$ concentrations in urine. It has been previously discussed whether these measurements should be carried out with or without application of a chelating agent such as DMPS. On the basis of $\mathrm{Hg}$ determinations in 490 women, Gerhard and colleagues ${ }^{12}$ have previously correlated data acquired before and after DMPS administration, and found a weak correlation between both series of data. Our results now allow us to verify this correlation on a larger and more representative set of data (see fig $4 \mathrm{~A}$ ).

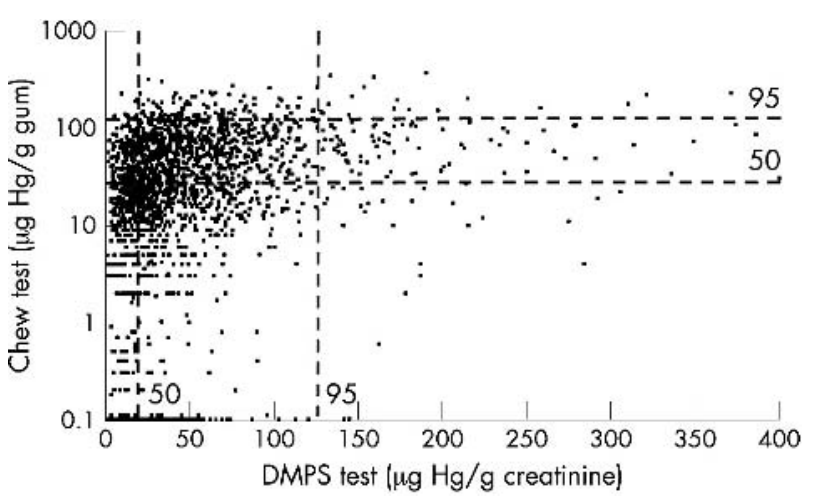

Figure 3 Correlation of $\mathrm{Hg}$ release from dental amalgams in standardised chew tests, with $\mathrm{Hg}$ body burden, as revealed by standardised DMPS tests. The 50th and 95th centiles are shown for both series of data (dashed lines). Two extreme values $(590 \mu \mathrm{g} \mathrm{Hg} / \mathrm{g}$ creatinine, $163 \mu \mathrm{g} \mathrm{Hg} / \mathrm{g}$ chewing gum; and $837 \mu \mathrm{g} \mathrm{Hg} / \mathrm{g}$ creatinine, $151 \mu \mathrm{g} \mathrm{Hg} / \mathrm{g}$ chewing gum) have been omitted for clarity.

In agreement with previous results we find that, although a general trend can be observed from the weak correlation (linear fit with a slope of 17.7 and an intercept of $17.2 \mu \mathrm{g}$ $\mathrm{Hg} / \mathrm{g}$ has a correlation coefficient $r^{2}$ of 0.34 ) between $\mathrm{Hg}$ concentrations in basal urine and urine after oral DMPS administration, this correlation no longer persists on an individual level, as already noted by Kistner. ${ }^{19}$ This feature is nicely illustrated in fig 4B. Moreover, basal urine gives a less significant expression of the $\mathrm{Hg}$ body burden than urine after DMPS administration, since in the former case $93 \%$ of the
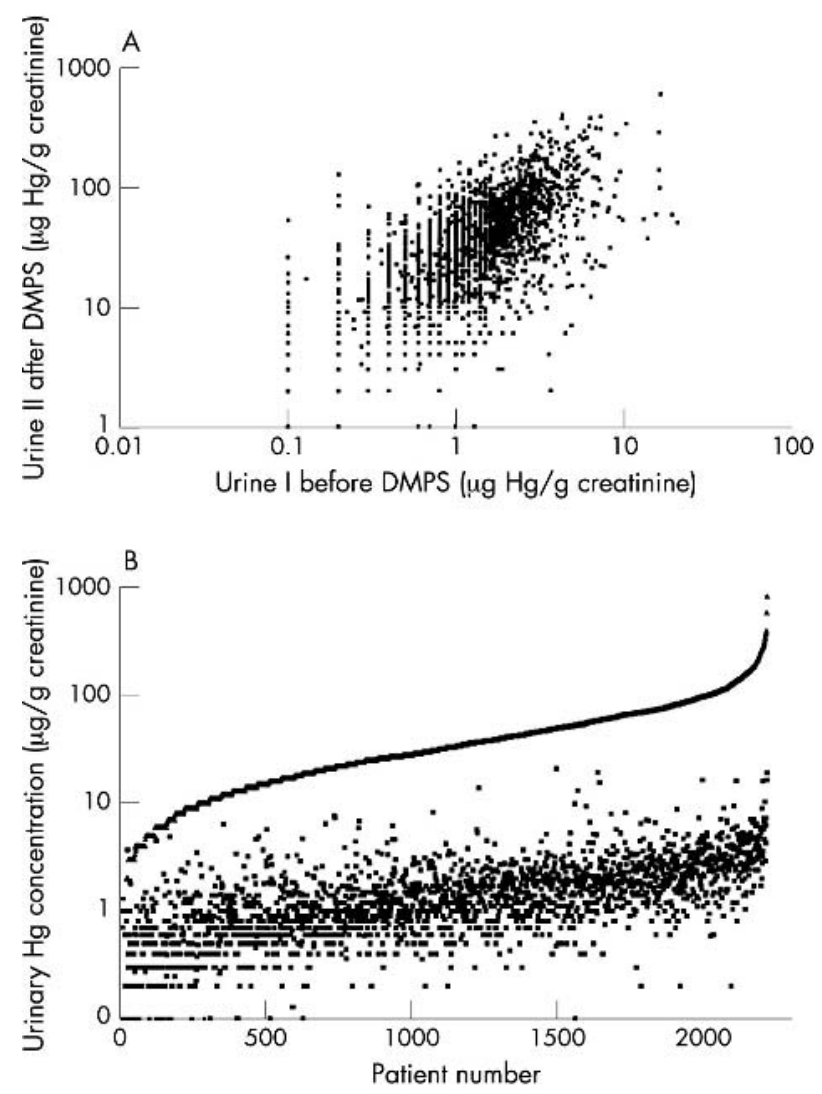

Figure 4 (A) $\mathrm{Hg}$ excretion in urine: correlation of basal urine content with DMPS induced excretion. (B) Urinary $\mathrm{Hg}$ excretion after DMPS (triangles) versus basal urine (squares). The plot illustrates the strong dispersion of the basal urine values for close DMPS test values. 
patients display $\mathrm{Hg}$ concentrations lying below the exposure limit of $4 \mu \mathrm{g} \mathrm{Hg} / \mathrm{g}$ creatinine, proposed by Schiwara and colleagues $^{20}$ (see discussion). Similar results have also been reported by other authors. ${ }^{12} 2122$

Consequently, only data from DMPS tests, chew tests, and hair tests are used for diagnostic and therapeutic purposes. Interpretation of the Mercury Triple Test is currently carried out in terms of multiples of medians-that is, physicians are provided with both absolute and relative data, as shown in fig 5. Patients are considered to suffer from significant $\mathrm{Hg}$ exposure due to dental amalgams if their chew test and DMPS test data exceed the corresponding medians by a factor of 3. Data from hair tests are less unambiguous, but can be used as supporting evidence.

In order to investigate the half-life of $\mathrm{Hg}$ in the human body, 11 female and 11 male patients from the group of 91 individuals having performed the Mercury Triple Test before and after amalgam removal have provided detailed information concerning the dates of their last filling removal. Several authors have previously investigated $\mathrm{Hg}$ content in basal urine following amalgam removal, and reported a half-life of 1-3 months for $\mathrm{Hg}$ in blood and urine. ${ }^{23-27}$ Figure 6 shows the evolution of the relative $\mathrm{Hg}$ concentration (that is, the ratio of $\mathrm{Hg}$ concentrations after and before amalgam removal) measured both in urine (urine II) after DMPS application, and in basal urine (urine I) of the 22 patients. The date of amalgam removal is used as time origin, assuming that, in absence of dental treatment or changes in occupational exposure, all relevant parameters remain constant over a few months.

Solid lines in fig 6 are of exponential fits, with exponential factors of -0.4 and -0.3 for the DMPS test (squares), and basal urine (triangles) data, respectively. This corresponds to a half-life of 1.7 and 2.3 months, respectively, which is in good agreement with results from previous studies. ${ }^{23-27}$

\section{DISCUSSION}

In order to evaluate the impact of $\mathrm{Hg}$ release from amalgams, we can compare the data obtained from the chew test with other common non-occupational sources of $\mathrm{Hg}$ exposure. The World Health Organisation (WHO) estimates average $\mathrm{Hg}$ concentrations in ambient air and drinking water to be $10 \mathrm{ng}$ $\mathrm{Hg} / \mathrm{m}^{3}$, and $0.5 \mu \mathrm{g} \mathrm{Hg} / \mathrm{l}$, respectively, which leads to an estimated daily intake of 0.2 and $1 \mu \mathrm{g} \mathrm{Hg}$, respectively. ${ }^{28}$ The most important environmental source of $\mathrm{Hg}$, however, is believed to be food, with an estimated additional intake of 2-20 $\mu \mathrm{g} \mathrm{Hg}$ per day. ${ }^{28}$ The provisioned tolerable weekly intake (PTWI) of Hg, established by the WHO in 1972, and reaffirmed in 1980 and 1988, is $5 \mu \mathrm{g} \mathrm{Hg}$ per $\mathrm{kg}$ of body weight, ${ }^{28}$ which corresponds to $350 \mu \mathrm{g} \mathrm{Hg}$ per week for a subject of $70 \mathrm{~kg}$. If we assume that, on average, one

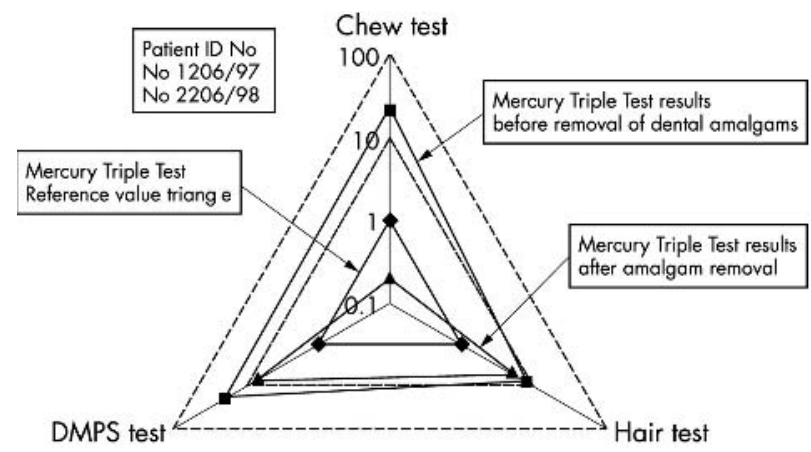

Figure 5 Mercury Triple Test expressed in multiples of median (MOM) for a patient before and six months after removal of 12 dental amalgam fillings compared to the median reference value triangle.

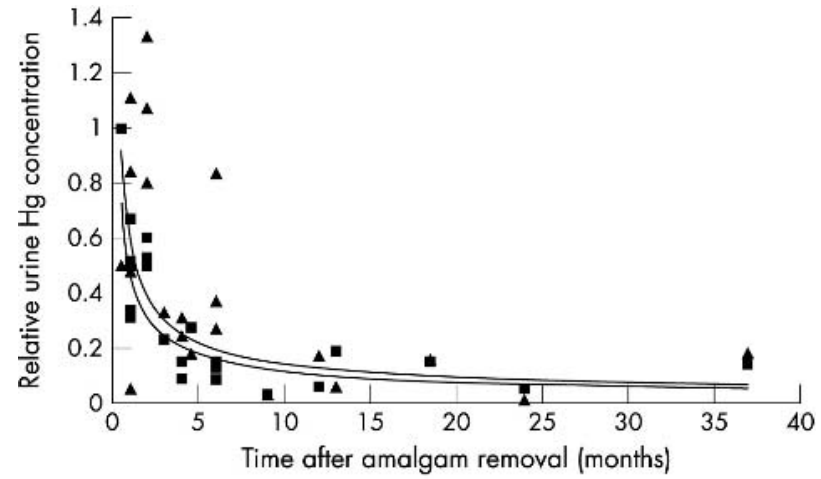

Figure 6 Dependence of the ratio of $\mathrm{Hg}$ concentrations after and before removal of dental amalgams, on the time interval after amalgam removal. $\mathrm{Hg}$ concentrations were determined after administration of DMPS (urine II, squares), and in basal urine (urine I, triangles).

individual performs about 30 minutes of chewing per day, a total weekly intake of $358 \mu \mathrm{g} \mathrm{Hg}$ is calculated for a subject with a chew test value of $27 \mu \mathrm{g} \mathrm{Hg} / \mathrm{g}$ gum (that is, the 50th centile value), at the high limit of weekly $\mathrm{Hg}$ exposure from food, drinking water, and air (that is, $148.4 \mu \mathrm{g} \mathrm{Hg}$ per week), calculated using the WHO data. Thus, the weekly Hg intake of most patients should be well below the PTWI, unless extremely mercury-rich food is consumed on a regular basis. However, for patients exceeding the 75 th centile value in chew tests, we calculate a weekly $\mathrm{Hg}$ intake of at least $512 \mu \mathrm{g}$, even at the low limit of environmental exposure (that is, $22.4 \mu \mathrm{g} \mathrm{Hg}$ per week), a value which exceeds the PTWI (for a $70 \mathrm{~kg}$ subject) by $46 \%$. Thus, our results show that, in many cases, the amount of $\mathrm{Hg}$ released from amalgam fillings determines whether $\mathrm{Hg}$ intake is below or above the PTWI.

Despite several authors claiming that the DMPS test adds no further information to that obtained from basal urine analysis, ${ }^{29}$ we found a stronger correlation between the number of amalgams and the $\mathrm{Hg}$ concentration in urine after DMPS administration than in basal urine (fig 7). This result is in agreement with the one found by Drasch and colleagues, ${ }^{22}$ who have described an exhaustive study concerning the diagnostic potential of the DMPS test. They have established a clear dependence of the number of amalgams on the $\mathrm{Hg}$ concentration in urine after oral DMPS administration. Hence, the DMPS test seems to reflect the additional kidney burden brought about by $\mathrm{Hg}$ release from dental amalgams, bearing in mind that DMPS favours $\mathrm{Hg}$ liberation mainly from the kidneys into urine, rather than from other major organs. ${ }^{22}$ Furthermore, the Hg concentrations we found in basal urine up to the 93th centile lie below $4 \mu \mathrm{g} \mathrm{Hg} / \mathrm{g}$ creatinine, which has been defined as the lower limit of environmental exposure..$^{20}$ Gerhard and colleagues ${ }^{12}$ and the Commission of Human Biomonitoring in Germany $\left(\right.$ HMB-I) ${ }^{30}$ have considered $5 \mu \mathrm{g} \mathrm{Hg} / \mathrm{g}$ creatinine as an exposure limit, which $96 \%$ of the patients included in this study do not exceed (the 99th centile corresponds to only $7 \mu \mathrm{g} \mathrm{Hg} / \mathrm{g}$ creatinine). One may add that in these low concentration ranges, uncertainties are rather high and no significant differences arise between values slightly below or above these limits. On the other hand, the high urinary $\mathrm{Hg}$ concentration range obtained after DMPS chelation has obviously to be considered as much more meaningful for evaluating the $\mathrm{Hg}$ body burden on the individual level, than the very low basal urine concentration range.

The comparison of urinary $\mathrm{Hg}$ concentrations of the 91 patients who performed the Mercury Triple Test before and after amalgam removal, shows that the concentration ranges "before" and "after" are better separated in the case of the 


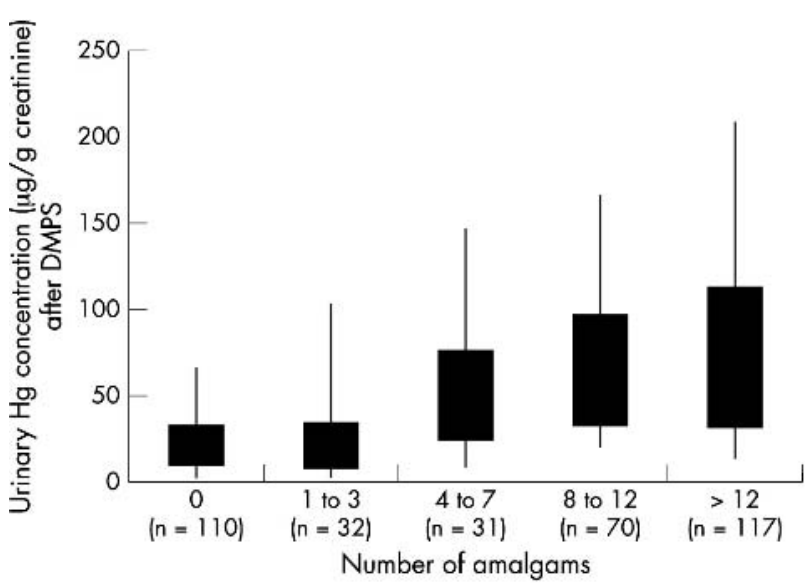

Figure 7 Box plot representing the relation between the number of amalgam fillings and $\mathrm{Hg}$ excreted in urine after DMPS administration. Rectangles $=25-75$ th centile range; vertical lines $=5-95$ th centile range .

DMPS test than when basal urine is used. In other words, the two DMPS test concentration ranges display significantly less overlapping values. Thus the latter, in this respect, again provides data that can be more easily related to $\mathrm{Hg}$ release from dental amalgams than those obtained from basal urine.

It may be noteworthy that, according to the study of Drasch and colleagues, ${ }^{22} \mathrm{Hg}$ concentration measured in whole blood, similarly to basal urine, is not an efficient parameter to assess the Hg kidney burden caused by dental amalgams. The very weak correlation between the amount of amalgams and $\mathrm{Hg}$ concentrations did not mirror the strong dependence of $\mathrm{Hg}$ concentrations measured directly in the kidney cortexes from corpses, on the number of dental fillings.

The hair test, at this stage, provides data that are sometimes difficult to align with those obtained from the two other tests. Data interpretation may be somewhat hampered because of the use of hair of various length or exogenous incorporation of $\mathrm{Hg}$. Nevertheless, the hair test can be seen as complementary to the other tests, in the sense that high $\mathrm{Hg}$ concentrations in hair together with low urinary and gum concentrations could for instance be attributed to recent amalgam removal.

\section{Conclusions}

Our results show that, in many patients, the amount of $\mathrm{Hg}$ released during chewing from dental amalgam fillings determines whether the weekly $\mathrm{Hg}$ intake lies below or above the PTWI. Oral Hg exposure plays a certain role in determining the body burden, as measured in urine, but not in hair. It is shown that significant $\mathrm{Hg}$ release from dental amalgams is a necessary but insufficient condition to obtain a high long term body burden. Thus, determination of $\mathrm{Hg}$ levels in several body matrixes is required to evaluate the magnitude and origin of the body burden of an individual patient. Together with the database presented here, the Mercury Triple Test provides a reliable diagnostic tool for evaluating the degree of $\mathrm{Hg}$ exposure of individual subjects.

Further work is aimed at the use of several hair segments of defined length from each Mercury Triple Test patient. This should facilitate establishing possible relationships between $\mathrm{Hg}$ content in hair grown up to several months prior to analysis, and $\mathrm{Hg}$ concentrations found in the other media.

\section{Authors' affiliations}

G Hansen, R Victor, E Engeldinger, C Schweitzer, Laboratoire

d'Hygiène du Milieu et de Surveillance Biologique, Laboratoire National

de Santé, Luxembourg

\section{REFERENCES}

1 Petering HG, Tepper LB. Pharmacology and toxicology of heavy metals: mercury. Pharmacol Ther 1976;1:131-51.

2 Leong CCW, Naweed IS, Lorscheider FL. Retrograde degeneration of neurite membrane structural integrity of nerve growth cones following in vitro exposure to mercury. Neuroreport $2001 ; 12: 733-7$.

3 Bernard S, Enyati A, Redwood L, et al. Autism: a novel form of mercury poisoning. Medical Hypothesis 2001;56:462-71.

4 Lorscheider FL, Vimy MJ, Summers AO. Mercury exposure from silver tooth fillings: emerging evidence questions a traditional dental paradigm. FASEB J 1995;9:504-8.

5 Staehle HJ. Gesundheitsrisiken durch zahnärztliche Materialien? Dt Ärzteblatt 1994;8:495-502

6 Drasch G. Recherche sur les foetus humains et les bébés. In: Lannoye P, ed. Amalgames dentaires et métaux lourds. Paris: Editions Frison-Roche, 2001.

7 See hHtp://www.ada.org.

8 Ministère de l'emploi et de la solidarité. Décision du 14 décembre 2000 relative à l'interdiction d'importation, de mise sur le marché et d'utilisation de certains amalgames dentaires. NOR: MESM0024039S, 2000.

9 Goldberg DM, Clarke AD. Measurement of mercury in human urine. J Clin Pathol 1970;23:178-83.

10 Wawschinek D. Zur toxikologischen Analyse des Quecksilbers im biologischen Material. Arch Toxicol 1972;29:107-15.

11 Schiwara HW, Daunderer M, Kirchherr H, et al. Bestimmung von Kupfer, Quecksilber, Methylquecksilber, Zinn, Methylzinn und Silber in Körpermaterial von Amalgamträgern. Klin Lab 1992;38:391-403.

12 Gerhard I, Waldbrenner P, Thuro H, et al. Diagnostik von Schwermetallbelastungen mit dem peroralen DMPS-Test und Kaugummitest. Klin Lab 1992;38:404-11.

13 Kleber JJ, Ganzert M, Zilker T. Quecksilberkonzentration nach DMPS-Gabe: Korrelation zur Anzahl der Amalgamfüllungen. In: Friberg LT, Schrauzer GN, eds. Status quo and perspectives of amalgam and other dental materials. Stuttgart: Georg Thieme Verlag, 1995.

14 Maugh TH. Hair a diagnostic tool to complement blood serum and urine. Science 1978;202:1271-3.

15 Krauss $\mathbf{P}$, Deyhle M, Maier $\mathrm{KH}$, et al. Field study on the mercury content of saliva. Toxicol Environ Chem 1997;63:29-46.

16 Schiele R, Erler M, Reich E. Speichelanalysen eignen sich nicht zur Bewertung der Quecksilberbelastung. Dt Ärzteblatt 1996;93:1135-6.

17 MAK- und BAT-Wert-Liste, 2001. Forschungsgemeinschaft D, ed. Maximale Arbeitsplatzkonzentration und Biologische Arbeitsstofftoleranzwerte. Weinheim: Wiley, 2002

18 Schiwara HW, Wittke JW, Gerritzen, et al. Analysenübersicht 2002/2003. Bremen, 2002.

19 Kistner A. Quecksilbervergiftung durch Amalgam: Dioagnose und Therapie. ZWR 1995;5:412-17.

20 Schiwara HW, Kunz J, Köster HD, et al. Umweltmedizinische Analysen; 6. Überarbeitete und erweiterte Auflage. Bremen, 1999.

21 lonescu G. Zahnlegierungen: Elektrochemische und biologische Materialprüfung. Forsch Komplementärmed 1996;3:72-7.

22 Drasch G, Scharl K, Roider G, et al. Aussagekraft des DMPS-Test auf Quecksilber. Umweltmed Forsch Prax 1997;2:2-10.

23 Snapp KR, Boyer DB, Peterson LC, et al. The contribution of dental amalgam to mercury in blood. J Dent Res 1989;68:780-5.

24 Molin M, Bergman B, Marklund SL, et al. Mercury, selenium, and glutathione peroxidase before and after amalgam removal in man. Acta Odont Scand 1990;48: 189-202.

25 Begerow J, Zander D, Freier I, et al. Long-term mercury excretion in urine after removal of amalgam fillings. Int Arch Occup Environ Health 1994;66:209-12

26 Molin M, Berglund JR, Mackert JR. Kinetics of mercury in blood and urine after amalgam removal. J Dent Res 1995;74:420.

27 Sandborgh-Englund G, Elinder CG, Langworth S, et al. Mercury in biological fluids after amalgam removal. J Dent Res 1998;77:615-24.

28 WHO. Health criteria and other supporting information. In: Guidelines for drinking-water quality, 2nd edn. Geneva: World Health Organisation, 1996;2:285-98.

29 Maas C, Schweinsberg F. Chemische Faktoren Teil 1: Metalle und Metalloide-Quecksilber. In: Beyer A, Eis D, eds. Pratische Umweltmedizin; Klinik, Methoden, Arbeitshilfen. Loseblattsystem, 7. Auflage, 1996.

30 Kommission "Human Biomonitoring" des Umweltbundesamtes. Stoffmonographie Quecksilber-Referenz-und Human -BiomonitoringWerte (HBM). 1999:522-32. 